\title{
Stage I Hypopharyngeal Carcinoma AJCC v8
}

National Cancer Institute

\section{Source}

National Cancer Institute. Stage / Hypopharyngeal Carcinoma A/CC v8. NCI Thesaurus. Code C133005.

Stage I includes: T1, N0, M0. T1: Tumor limited to one subsite of hypopharynx and/or 2 $\mathrm{cm}$ or smaller in greatest dimension. N0: No regional lymph node metastasis. MO: No distant metastasis. (AJCC 8th ed.) 